\title{
Cytology of lesions arising in and around operative scars: short series of four cases
}

\author{
Ganorkar SD ${ }^{1}$, Poflee $\mathrm{SV}^{2}$, Gaikwad $\mathrm{AL}^{3}$, Pande $\mathrm{NP}^{4}$, Shrivastava $\mathrm{AC}^{5}$, Shrikhande $\mathrm{AV}^{6}$ \\ ${ }^{1}$ Dr. Shweta D. Ganorkar, M.B.B.S, Final Year Resident Pathology, ${ }^{2}$ Dr. Sandhya V. Poflee, M.B.B.S, MD Pathology, \\ Assistant Professor, ${ }^{3}$ Dr. Amrapali L. Gaikwad, M.B.B.S, MD Pathology, Assistant Professor, ${ }^{4}$ Dr.Nandu P. Pande, \\ M.B.B.S, MD Pathology, Associate Professor, ${ }^{5}$ Dr. Alok C. Shrivastava, M.B.B.S, MD Pathology, Associate Professor, \\ ${ }^{6}$ Dr. Anuradha V. Shrikhande, M.B.B.S, MD Pathology, Professor and Head Department of Pathology. All are affiliated \\ with Indira Gandhi Government Medical College \& Hospital, Nagpur, Maharashtra, India
}

Address for correspondence: Dr.Shweta D. Ganorkar, Email: shwetaganorkar87@gmail.com

\begin{abstract}
Fine needle aspiration cytology (FNAC) is an established and valuable method for morphological diagnosis of soft tissue masses and confirmation of their local recurrence or metastasis. This study aims to highlight role of FNAC in confirmation of soft tissue recurrences that occurred in and around operative scars. Wet fixed \& air dried smears were made from the material aspirated from four representative cases and stained routinely. Preoperative cytodiagnosis could be given in all cases. In two cases arising in previous scars of benign nerve sheath tumors, FNAC confirmed recurrence in one case and could suggest increased grade of lesion in the other. In the third case, in which initial nature of the lesion was not known, FNAC diagnosed scar endometriosis on two occasions. In fourth case local recurrence of extra abdominal fibromatosis was confirmed. Histopathological correlation was available in all cases. FNAC confirmed recurrence and could suggest diagnosis on scanty material.
\end{abstract}

Keywords: Recurrence, Soft Tissue Lesions, Operative Scars, Fine Needle Aspiration Cytology (FNAC)

\section{Introduction}

Soft tissue lesions are frequently encountered in everyday practice by clinicians and radiologists however, their characterization remains problematic [1]. Fine Needle Aspiration Cytology (FNAC) is an established modality for morphological diagnosis of soft tissue lesions [2,3]. Systematic clinical history, lesion location, mineralization on radiographs and morphology on cytology together proves helpful in making early diagnosis and planning treatment, especially in recurrent lesions [4]. FNAC is a least invasive method for sampling that does not compromise the tissue planes and is cost effective for patients [5]. Effective use of FNAC in four representative cases arising in operative scars is described.

\section{Case 1}

A 35 years old female came with complaint of a gradually increasing painless swelling over right arm

Manuscript Received: $10^{\text {th }}$ Sept 2015

Reviewed: $4^{\text {th }}$ Oct 2015

Author Corrected: $11^{\text {th }}$ Oct 2015

Accepted for Publication: $22^{\text {nd }}$ Oct 2015 since 8 months. She gave history of excision of a similar swelling over same site 3 years back. There was no history of similar swellings over other body parts neither in any family member. Her medical records mentioned that the initial swelling was neurofibroma on histopathological examination.

On examination, a fine scar of length $3.5 \mathrm{~cm}$ was seen on middle one third of right arm. Just Below the scar, a swelling of size $3 \times 1.5 \mathrm{~cm}$ was palpated that was firm, tender and partially mobile along horizontal axis (Fig 1a).Cytology study was advised. Cytology smears showed cellular fragments of spindle cells in clusters and many scattered single cells in background. Cells were dispersed in the fibrillary stroma. Cell nuclei were plump, elongated and at places wavy with bland chromatin. Cytological diagnosis of benign nerve sheath tumor favoring neurofibroma was given. (Fig 1c).

The excised tumour was firm uncapsulated with glistening white cut surface (Fig 1b) and microscopy 
revealed interlacing bundles of spindle cells with elongated and wavy nuclei admixed with collagenfibres in mucoid background. (Fig1e).There was no evidence of atypical features and mitoses. The cytodiagnosis of the recurrent swelling was confirmed on histopathology and also correlated with histopathology report of previously operated swelling of neurofibroma.

\section{Case 2}

A 30 years old male was referred for FNAC of a painful unilateral inguinal swelling with clinical suspicion of infective lymphadenitis. Patient had an extremely painful swelling in left groin of 6 months duration and difficulty in walking. There was no history of fever, trauma or any other associated illness. He gave past history of excision of a swelling in the same region five years back. Personal and family history was not significant.

On examination an ugly scar of length $5 \mathrm{~cm}$ was seen along upper $1 / 3^{\text {rd }}$ anteromedial surface of left thigh. A swelling of size $5 \times 3 \mathrm{~cm}$ was noted along upper part of scar and over medial part of inguinal ligament. It was tender, soft to firm, with ill-defined margins and reduced mobility (Fig 2a).

Fine needle aspiration caused intense pain along left lower extremity. FNA smears showed abundant cellularity of large cohesive fragments and a few scattered spindle cells with filamentous cytoplasm. Nuclei were mostly wavy and at places fish hook nuclei with bland chromatin were appreciated. Focal areas of nuclear palisading were seen (Fig 2b). Cytological impression of cellular neurilemoma was conveyed.

Histopathological examination of the excised swelling (Fig2c) confirmed the cytodiagnosis.

\section{Case 3}

A 32 years old nulliparous female during investigations for infertility, was noticed to have a small tender swelling in left groin. The patient gave history of increase in pain and size of the swelling during menstrual cycle (catamenial exacerbation) since 5 months. A blackish scar was seen above the swelling. The nature of previous surgery was not known and report was not available. Beneath the scar, lateral to pubic tubercle, a firm, tender, discrete swelling of $0.5 \mathrm{x}$ $0.5 \mathrm{~cm}$ was palpated that fluctuated in size during each cycle. It was not associated with signs of inflammation (Fig 3a).

Cytology smears showed bimodal population of endometrial glandular cells and stromal cells and few singly scattered hemosiderin laden macrophages in the background of old blood and cell debris (Fig 3b).On the basis of clinical context and cytomorphological features, a diagnosis of scar endometriosis was given. Histopathological features of the excised swelling were consistent with cytological diagnosis (Fig 3c).

After one and half years, the patient came with similar complaints. The swelling at the time of second recurrence was again found to be located around the previous scar. FNAC ofthe second recurrent swelling was performed and showed cytological features consistent with diagnosis of endometriosis without cellular or nuclear atypicality.

\section{Case 4}

A 36years old female came with a gradually increasing swelling over right upper arm since 2 months. She was operated upon for a swelling at the same site one year back. The previous swelling was diagnosed as desmoids fibromatosis on histopathology in our laboratory.

The present swelling was of size $5 \times 3 \mathrm{~cm}$, hard in consistency, non-tender and located beneath a $6 \mathrm{~cm}$ long unsightly surgical scar mark along lateral surface of right arm (Fig 4a).The swelling was fixed to underlying structures with irregular and ill-defined margins.

FNAC had to be repeated twice with a wide bore needle (24 gauge) to obtain material. Second attempt to sample the swelling was made under ultrasonic guidance that also gave scanty yield. Smears showed scanty cellularity of spindle cells entrapped in collagen fragments. There was no evidence of cellular, nuclear pleomorphism or increased mitotic activity. In view of the clinical history and previous histopathologyreport, cytodiagnosis of extra abdominal fibromatosis could be given (Fig 4b).

Sections from the mass showed interlacing bundles of spindle cells separated by abundant collagen. The cells infiltrated the surrounding muscle tissue (Fig 4d).Cytodiagnosis of the recurrentswelling was in thus concordance with histopathology diagnosis of extra abdominal desmoidfibromatosis. 

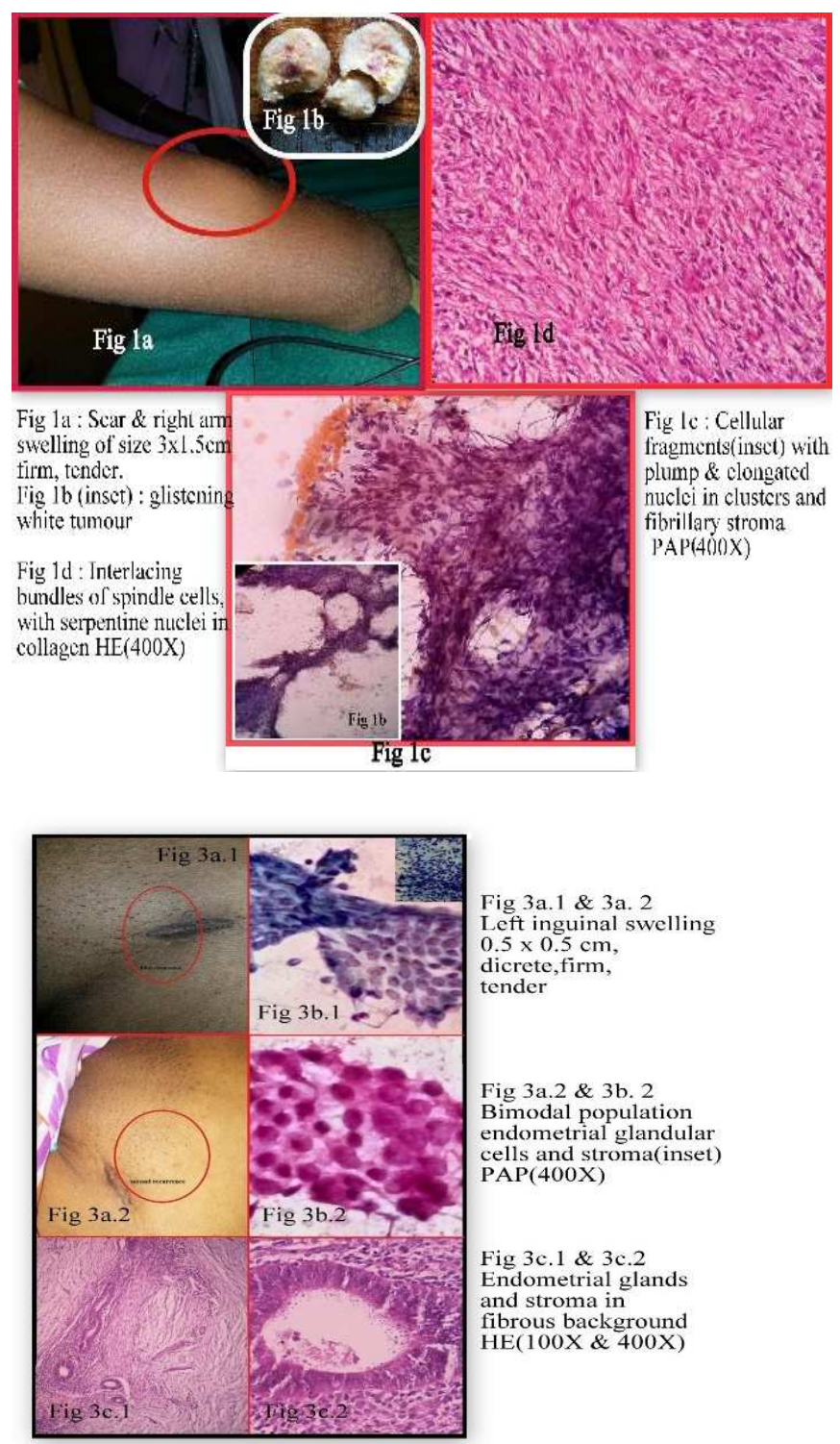

\section{Discussion}

Many tumors and tumorlike lesions that occur in soft tissues are known for frequent local recurrences. The recurrent lesion may show biological grade of the original lesion or a higher grade on morphological examination. An unexpected lesion may occur in local recurrence. FNAC is especially valuable for confirmation of a recurrence or metastasis [5]. FNAC plays an important role in triaging the patients and narrowing the differentials with minimum tissue trauma. Preoperative cytological diagnosis in a few cases may change the treatment modality that may become more aggressive and include chemoradiation for any recurrent lesion with high grade [6]. Rapid

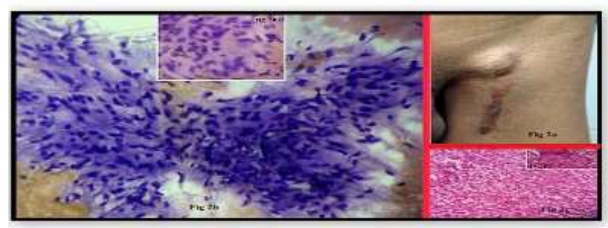

Fig 2a : Left inguinal swelling of size $5 \times 3 \mathrm{~cm}$, tender, fîrm, partially fixed

Fig 2b: Cohesive fragments fish hook nuclei, pointed nuclear ends, palisading nuclei(fig 2 bl inset), filamentous cytoplasm MGG(400X)

Fig 2c: Alternating hypo and hypercellular areas, nuclcar palisading ( $\mathrm{fig} 2 \mathrm{c} 1$, inset , hyalinised thick blood vessels

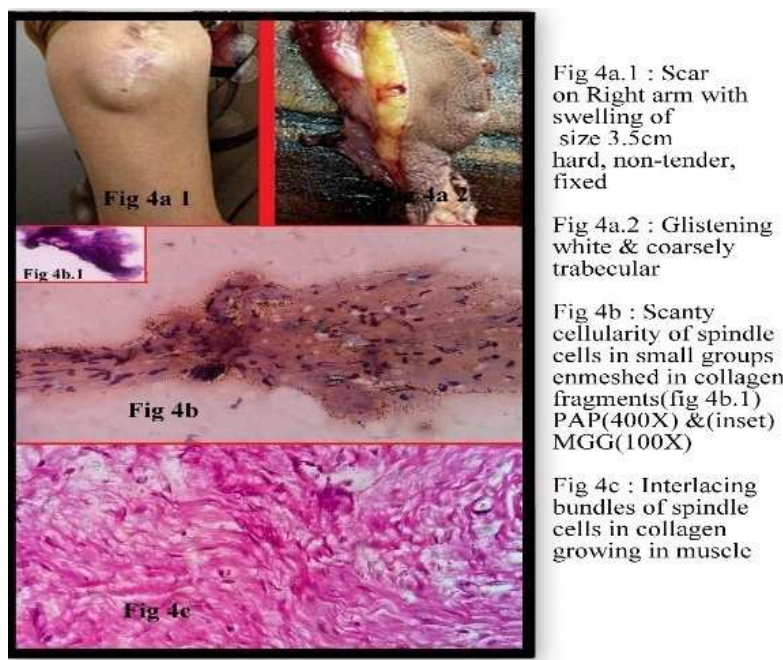

cytodiagnosis relieves anxiety of the patient about the disfiguring recurrent swelling that occurs in or around the previous operative scars.

Neurilemomaand neurofibroma both are classified under benign nerve sheath tumors that can be differentiated on the basis of cytological features in most cases [7]. A neurilemomaoften raises the possibility of a malignancy because thick aspirated tissue fragments appear cellular on smears, particularly in the cellular neurilemomavariant.This false impression of malignancy is heightened even further with an ancientneurilemoma due to presence of large, 
bizarre nuclei. Densely cellular fascicles alternating with hypocellular myxoid areas, necrosis and heterologous differentiation favor a malignant peripheral nerve sheath tumor (MPNST) [5]. The treatment of a recurrent benign nerve sheath tumor is surgical, either for cosmetic purpose or when the local pressure symptoms develop [8].Additional adjuvant radiotherapy isadvocated for MPNST [9]. Exact preoperative diagnosis with biological grade in first two recurrent nerve sheath tumor cases of the series resulted into their adequate surgical excision. Cytology could identify higher grade of the recurrent lesion preoperatively that gave clear idea about extent of surgical excision second time.

Endometriosis is the presence of functioning endometrium outside the uterus. It commonly occurs in women of reproductive age, near abdominal wall scars, in pelvic region and in many uncommon extra pelvic sites [10]. History of catamenial exacerbation, location of a firm, tender swelling near a previous operative scar and characteristic cytological features point toward diagnosis of scar endometriosis [11].FNAC is a reliable and relatively atraumatic investigation for diagnosis of primary as well as recurrent lesion and to monitor treatment [12].In Our third case in which nature of the lesion was confirmed as scar endometriosis, which was considered as the cause of infertility. This resulted into change of her treatment plan accordingly.

Desmoid tumor is a lesion of mesencymal origin composed of fibrous tissue [13]. It represents locally aggressive form of musculoaponeuroticfibromatosisthat needs different therapeutic approach than sarcomas [14].Abdominal location is common and typically occurs in young women. Extra abdominal tumors though rare, are seen in pelvic or pectoral girdle region over wide age range [15].Antecedent surgical trauma might play a role in the development of desmoids tumour [16]. Hence, sampling with FNAC is to be preferred. FNAC for preoperative diagnosis of recurrent fibromatosis in case 4 reduced the tissue trauma to minimum. Secondly the patient received chemoradiation before repeat surgical excision on the basis of cytological diagnosis.

\section{Conclusion}

FNAC has a definite and valuable role in confirmation of local recurrence in operative scars and can suggest diagnosis even on scanty material obtained from recurrent lesions.Preoperative knowledge of morphological nature and grade of lesion immensely helps in surgical treatment planning.

\section{References}

1. Wu JS, Hochman MG. Soft-tissue tumors and tumorlike lesions: a systematic imaging approach. Radiology $2009 \quad$ Nov;253(2):297-316.doi: 10.1148/radiol.2532081199.

2. Domanski HA. Fine-needle aspiration cytology of soft tissue lesions: diagnostic challenges.DiagnCytopathol.2007 Dec;35(12):768-73.

3. Dey P, Mallik MK, Gupta SK, Vasishta RK. Role of fine needle aspiration cytology in the diagnosis of soft tissue tumours and tumour-like lesions. Cytopathology.2004 Feb;15(1):32-7.

4. Pant A, Julfiqar, Huda N, Aslam M. Benign solitary Schwannoma of right ulnar nerve - A case report. ActaMedica International. 2015; 2(1):164-167.

5. Qian X. Soft tissue. In: Cytology: Diagnostic Principles and Clinical Correlates. Cibas E, Ducatman B, eds. ${ }^{\text {rd }}$ Edition. Philadelphia Pa:Saunders; 2009. Pg451-453.

6. Geller DS, Gebhardt M. Malignant Peripheral Nerve Sheath Tumors (MPNST)[Internet].2006 [Cited 2006]. Availiable from sarcomahelp.org/mpnst.html.

7. CzerniakB,Tuziak T. Soft Tissue Lesions. In: Koss' Diagnostic Cytology and Its Histopathologic Bases. Koss, Leopold G,Melamed, Myron R eds. 5th Edition. Philadelphia Pa:Lippincott Williams \& Wilkins;2006. Pg1325-1328.

8. Dimitrova V, Yordanova I, Pavlova V, Valchev V, GospodinovD,Parashkevova B, Balabanov Ch. A case of neurofibromatosis type 1. J of IMAB 2008; 14(1):6367. doi: 10.5272/jimab.14-1

9. Kar M, Deo SV, Shukla NK, Malik A, DattaGupta S, Mohanti BK et al. Malignant peripheral nerve sheath tumours (MPNST)- Clinicopathological study and treatment outcome of twenty four cases. World J Surg Oncol2006 Aug 22;4:55.

10. Female reproductive system: Uterus-corpus. In: Rosai and Ackerman's Surgical Pathology.Rosai J ed. 10th ed. St. Louis: Mosby; 2012. Pg1486-7. 
11. Medeiros Fd1, CavalcanteDI, Medeiros MA, Eleutério J Jr. Fine-needle aspiration cytology of scar endometriosis: study of seven cases and literature review. DiagnCytopathol 2011 Jan;39(1):18-21. doi: 10.1002/dc.21319.

12. Poflee S, Bode A, Mahana S. Cytodiagnosis of scar endometriosis .CytoJournal 2014;11:1. doi: 10.4103/1742-6413.126222.

13. Zampieri N, Cecchetto M, Zorzi MG, Pietrobelli A, Ottolenghi A, Camoglio F. An unusual case of extraabdominal desmoidtumour. Eur $\mathrm{J}$ Cancer Care (Engl).2010 May;19(3):410-2. doi: 10.1111/j.13652354.2008.01002.x. Epub 2009 Aug 26.
14.Stoeckle E, Coindre JM, Longy M, Binh MB, Kantor G, Kind M et al. A critical analysis of treatment strategies in desmoidtumours: a review of a series of 106 cases.Eur J SurgOncol.2009 Feb;35(2):129-34.doi: 10.1016/j.ejso.2008.06.1495. Epub 2008 Aug 29.

15.Fibromatoses, In:Enzinger\& Weiss's Soft tissue tumors. Weiss SW, Goldblum JR eds. $5^{\text {th }}$ Edition. Philadelphia PA:Mosby 2008. Pg237-246.

16. Satsuma S, Yamamoto T, Kobayashi D, Yoshiya S, Marui T, Akisue T et al. Extraabdominaldesmoid tumor in a surgical scar of a patient with Sprengel's deformity. J Pediatr Surg. 2003 Oct;38(10):1540-2.

\section{How to cite this article?}

Ganorkar SD, Poflee SV, Gaikwad AL, Pande NP, Shrivastava AC, Shrikhande AV. Cytology of lesions arising in and around operative scars: short series of four cases. Int J Med Res Rev 2015;3(9):1105-1109. doi: 10.17511/ijmrr.2015.i9.202. 